\title{
A Discourse Perspective of Topic-prominence in Chinese EFL Learners' Interlanguage
}

\author{
Shaopeng Li (Corresponding author) \\ School of English Studies, Shanghai International Studies University \\ 550 Dalian Road (W), Hongkou District, Shanghai 200083, China \\ E-mail: lishaopeng99@126.com \\ Lianrui Yang \\ School of Foreign Languages, Ocean University of China \\ 238 Songling Road, Laoshan District, Qingdao 266100, China \\ E-mail: yanglianrui@yahoo.com.cn
}

Received: 25-01- 2014

Accepted: 31-03- 2014

Published: 01-07- 2014

doi:10.7575/aiac.ijalel.v.3n.4p.190

URL: http://dx.doi.org/10.7575/aiac.ijalel.v.3n.4p.190

The research is financed by China Scholarship Council. No. 201306900018

\begin{abstract}
The present study aims to investigate the general characteristics of topic-prominent typological interlanguage development of Chinese learners of English in terms of acquiring subject-prominent English structures from the discourse perspective. We have selected as the research target "topic chain" which is the main topic-prominent structure in Chinese discourse and "zero anaphora" which is the most common topic anaphor of topic chain. Topic structures mainly appear in Chinese discourse in the form of "topic chain" (Wang, 2002; 2004). Actually, in the event of a topic chain, research on topic structures should go into the typical range of discourse. Two important findings were yielded by the present study. First, the characteristics of Chinese topic chain are transferrable to the interlanguage of Chinese EFL learners, thus resulting in overgeneralization of zero anaphora; second, interlanguage discourse of Chinese EFL learners reflects the characteristics of a second language acquisition process from topic-prominence to subjectprominence, thus lending support to the discourse transfer hypothesis.
\end{abstract}

Keywords: topic-prominence, subject-prominence, topic chain, zero anaphora, discourse transfer

\section{Introduction}

In terms of information structure in discourse, English and Chinese are typologically different languages. Chinese is a topic-prominent language in which topic plays an important role in the formation of a sentence, whereas English belongs to the group of subject-prominent languages in which subject is an indispensable element that determines the English sentence pattern (Li \& Thompson, 1976). In second language acquisition research, quite a number of empirical studies have been conducted based on the language typological classification of subject-prominence (SP) and topicprominence (TP) (Cai, 1998a\&b; Givón, 1983; Jung, 2004; Sasaki, 1990; Shi, 1989; Yang, 2008). However, previous studies usually explored the TP/SP issue from the syntactic perspective, ignoring the discourse function of the Chinese "topic", as well as the influence of the key topic structure in Chinese discourse. Consequently, topic chain in interlanguage discourse of Chinese learners has scarcely been investigated. Topic chain means "a set of clauses linked by a topic in the form of zero anaphora" (Chu, 1998: 324) and an example of a topic chain will be provided later in the following section of this paper.

The present study attempts to move beyond syntax to investigate topic-prominence in the interlanguage of Chinese EFL learners from the discourse perspective. The research target for this chapter is topic chain which is the main topicprominent structure in Chinese discourse and zero anaphora which is the most common topical anaphor in topic chain. Topic structures mainly appear in Chinese discourse in the form of "topic chain" (Wang, 2002; 2004). Zero anaphora can be used in topic chain which contains at least two clauses, and this is the reason why we have chosen it as our research target. It is hoped that the findings of the present study will shed light on the development of Chinese EFL learners' interlanguage from topic-prominence to subject-prominence from the perspective of discourse. The typological analysis above provides guidelines for identifying characteristic patterns in the study of any language and for analysis of interlanguage in terms of acquisition of these patterns.

\subsection{Topic and Topic Chain}

Topic in a topic-prominent language is characterized by a continuity of the referent in discourse which represents the 
availability or identifiability of the referent for the speakers and listeners involved (Givón, 1983). Topic explicitly establishes a point of reference for the ensuing discourse by introducing new information, that is, information that is not recoverable from the preceding text.

A topic chain has always been looked on as a self-contained unit, either at the level of syntax or at the level of discourse. However, the previous studies have indicated that topic chain does not always correspond to the traditional unit of a sentence. What's more, the domain of a topic chain can always cross the boundaries of not only sentence but also paragraph. This seems to show that a topic chain should be considered as a unit which is larger than a sentence or even a paragraph. Topic chain is a commonly seen phenomenon in Chinese and Referring expressions that can be deduced contextually by the reader are frequently omitted in Chinese discourse (Yeh \& Chen, 2003). The referring expressions have enough topic continuity and thus enough cohesion for readers or listeners to find the particular stretch of discourse coherent and more importantly, it is the overt identical topic that forms a topic chain.

Tsao (1979) is believed to have been the first researcher to employ the term "topic chain". He thought that a topic chain is actually a piece of discourse which is made up of one or more clauses, headed by a topic linking all the clauses. A topic chain actually functions as a discourse unit in Chinese (Tsao, 1990). Chu (1998) put forward a more restricted viewpoint which assumes that topic chain can only be identified at the level of discourse when it serves as an interclausal link. Therefore, he defined a topic chain as "a set of clauses linked by a topic in the form of zero anaphora" (p. 324). According to him, it is meaningless to talk about a topic chain within a single clause or sentence. According to $\mathrm{Li}$ (2005), a topic chain is "a chain of clauses sharing an identical topic that occurs overtly once in one of the clauses". All the other clauses are linked to the chain by zero NPs (zero NPs, marked as "Ø" in the analysis). In the following example, the overt identical NP "that car" is the topic in the topic chain which contains six clauses:

(1) Na liang che NP/jiaqian tai gui, ØNP yanse ye buhao, wo PRON/bu xihuan

that CLF car price too expensive color either not good I not like

$\varnothing N P, \varnothing P R O N$ bu xiangmai $\varnothing N P$ $\varnothing P R O N$ zuotian qu kan le yixia ØNP , ØPRON

not want buy yesterday go look

hai kai le yihuier ØNP, ØРRON haishi bu xihuan ØNP、

also drive a while still not like

= That car is too expensive, and its color is not good. $\underline{\mathbf{I}}$ don't like $\underline{\text { it }}$ and don't want to buy it. I went to see $\underline{\text { it }}$ yesterday and I drove it for a short time, but $\underline{\mathbf{I}}$ still dislike $\underline{\text { it. }}$.

As we can see, six unspecified NPs are identified in (1). The clauses with the unspecified NPs and the one with the overt coreferential NP ("that car" ) are considered to form a chain with the overt NP being the topic of the chain. The topic is usually mentioned once at the beginning of a chain in the first clause, and the following chain of clauses shares one single topic.

\subsection{Zero Anaphora}

Anaphora in Chinese can be classified into three categories, which are zero, pronominal and nominal forms respectively (Chen, 1987). The following is an example quoted from Chen (1987) :

(2) Tang Mingde jinghuang de wang wai pao, Ø zhuang dao yi ge dahan de

Tang Mingde in panic out ran bumped onto a big guy's

Shenshang, Ta kan qing le naren de meiyan, Ø renchu naren shi shui.

body he saw clearly that guy's eyes recognized that guy was who

=Tang Mingde ran out in panic and bumped onto a big guy. He saw that guy's eyes clearly and recognized who that guy was.

In this example, "Ø” and"ta"co-refer with "Tang Mingde", and "na ren"co-refers with "yi ge da han". "Ø”, "ta"and "na ren" represent three kinds of anaphor in Chinese: a zero, a pronoun and a full noun phrase respectively.

In Chinese discourse, the anaphor is frequently in the form of a zero morpheme, due to its prominence in discourse ( $\mathrm{Li}$ \& Thompson, 1981), which is termed as zero anaphora (hereafter ZA), zero anaphors are generally understood from the context and left unspecified. ZA occurs much more frequently in Chinese than in English. In English, even when the intended referent can be easily understood from the context, the presence of those pronouns is still required to complete a clause in a discourse. In fact, the structural completion of a sentence is so important in English that the language has to resort to a suppositional pronoun "it" to fill in the slot of the grammatical subject. ZA is such a common linguistic device in Chinese that it may occur in almost any syntactic position in the sentence where a noun or a pronoun could appear. Li and Thompson (1981: 657) asserted that "a salient feature of Mandarin grammar is the fact that noun phrases that are understood from context do not need to be specified".

\section{Literature Review}

\subsection{Typological Transfer and Discourse Transfer}

TP Chinese and SP English, as two salient typological languages, share some similarities but retain more differences. Consequently, when a TP Chinese learner of English makes an attempt to acquire the SP English, both his previous knowledge of L1 and the present knowledge of L2 are resorted to to decide whether TP features are available in this SP 
English. Previous research has shown different results on the different roles of language typology in SLA. One claim is that the typology of topic/subject prominence is not transferable. The opposing view is that learners' L1 plays a role in their L2 learning and that typological transfer is possible in their L2 production.

Discourse transfer refers to the use of some of the discourse patterns of the learner's L2 in the same way in which they are employed in the learner's L1 (see Kasper \& Schmidt, 1996; Kellerman, 1995; Wu, 2001). Discourse transfer is operationally defined in the present study as what happens when the language learner transfers L1-based discourse patterns to the L2 context. Discourse transfer studies focus on an L1 discourse strategy that is negatively transferred to L2 contexts, and demonstrates how learners transfer the L1 criteria of discourse patterns to the L2 performance. Along this line, discourse transfer studies look at the structure of L2 learner's output to see how it is organized. Some previous studies (Kasper, 1992; Kellerman, 1983) view discourse transfer as a cognitive activity in that it reflects active selection of some discourse patterns in the learners' L2 to be used in the same way in which they are employed in the learner's L1, and focuses on the learner's cognitive contribution in actively selecting and producing L1-based discourse patterns in L2 contexts. The cognitive view emphasizes the relationship between L2 input, learner internal processing, and learner output in order to discover how the existing knowledge of the L1 influences the acquisition of L2. Following this research tradition, Bartelt (1992) states that "discourse transfer is a rule-governed cognitive process" (p. 113), in which the known rules of the native language are used as hypotheses in mastering the second language. As a topicprominent language, Chinese is characterized basically as a highly context-dependent language, which stresses semantic coherence rather than formal cohesion, whereas English is subject-prominent, which is a structure dependent language (Wang, Hsu and Chen, 1998). Chinese is called a discourse-oriented language (Huang, 1984, 1989; Shi, 1989; Tsao, 1977) with a rule of Topic NP Deletion, "which operates across discourse to delete the topic of a sentence under identity with a topic in a preceding sentence. The present study will focus on the discourse patterns of the learners' L2 to see how they are organized and try to explore whether Chinese EFL learners will actively select and produce L1-based discourse patterns in L2 contexts due to the difference between Chinese and English discourse mentioned above.

\subsection{Previous Studies on Topic Prominence in Interlanguage}

The introduction of the notion of topic prominence by Schachter \& Rutherford (1979) and Rutherford (1983) into the research field of SLA has triggered quite a number of studies concerned with this issue. Fuller \& Gundel's (1987) study yielded two findings. First, there was no difference in topic-prominence between the speakers of topic-prominent and subject-prominent languages in their English interlanguage narratives. Second, L2 interlanguage as a whole was more topic-prominent than that of L1 native speakers of English. This finding suggests that TP/SP is not a transferable typology and L2 learners of different language backgrounds may go through a similar stage of universal TP. The reason why Fuller and Gundel got the results might be the students recruited in their study. Perhaps they were so advanced that any L1 effects would wash out. In contrast, our cross-sectional study may offer counter evidence against such a washout, since the students of low proficiency do show what we would expect if transfer is at work.

Rutherford (1983) examined the L2 written production by TP L1 speakers (Chinese, Japanese and Korean) at different L2 proficiency levels and detected the evidence of overproduction of TP structures by TP speakers, especially Chinese speakers whose language has typical TP features. Jin (1994) conducted an empirical experiment to study the behavior of 46 adult native speakers of English learning Chinese as a second language. Two important results emerged from his study: First, L2 learners with very limited proficiency in Chinese tended to rely on structures that are similar to English. Second, as soon as some TP features in learners' interlanguage increased significantly, other clustered TP structures such as double nominative constructions began to occur. Jin argued that these findings might contribute to SLA theory in that the data from English native speakers learning Chinese did not support Fuller \& Gundel's (1987) proposition of a universal topic-comment stage during L2 learners' early acquisition of the language. Jin found in his study that when learning Chinese, the English learners went through a process of systematically transferring English SP features to Chinese until they reach a requisite proficiency when the concept of topic emerges, thus supporting Rutherford (1983)' claim on typological transfer.

One of the researchers of this paper (Yang, 2008) showed that the Chinese students at the preliminary level are strongly influenced by their native language and transfer their Chinese form/function to English directly. TP properties are dominant, though there is substantial evidence of SP properties in the interlanguage of Chinese students of English. The Chinese students of English at each proficiency level have employed TP structures in their interlanguage to a certain extent. However, there is a general tendency that the frequency of using TP features in the interlanguage decreases and that of using SP structures increases with the development of learners' English proficiency level.

In sum, two conflicting claims have emerged from the studies reviewed above: One is that the process of L2 acquisition is actually characterized by an early universal topic-comment stage, independent of a learner's native language; the other is that the early TP stage is evidence of typological transfer from L1 to L2. Such conflicting conclusions may arise from the fact that the studies above were based only on data concerning English as a second language, an SP language.

Although the previous studies have shown the possibility of typological transfer by conducting research on interlanguage, the role of topic/subject prominence typology in L2 acquisition is still not clear as these studies have explored this issue purely in a syntactic way. It remains to be seen whether previous findings can be substantiated from the perspective of discourse. It remains to be seen whether some L2 sentence-level discourse features will pattern in the same way that they do in the learner's L1. That is, whether the language learners will transfer L1-based discourse patterns to interlanguage. Accordingly, the present study will look at the structure of L2 learner's output to see how it is organized. Therefore, the current study attempts to provide additional cross-linguistic examination by a look at how 
learners perform on a translation task, in the belief that the findings enable us to better understand the role of language typology in SLA.

\section{Research Questions and Hypotheses}

The study reported here explores whether the TP features in Chinese discourse exist in the interlanguage of Chinese learners of English. In order to deepen our understanding on the topic-prominent features of Chinese learners of English with different proficiency levels, we have had the following research questions guide our entire research:

(1) Do learners use fewer topic-prominent TP structures and more subject-prominent structures at higher proficiency levels?

(2) Is zero anaphora transferable in connected discourse?

Based on the evidence of some previous studies (Cai, 1998a\&b; Givón, 1983; Jin, 1994; Sasaki, 1990; Shi, 1989; Yang, 2008; Yip, 1995), we put forward the following two hypotheses:

(1) The characteristics of Chinese topic chain will be transferred to the interlanguage of Chinese EFL learners, thus resulting in the overgeneralization of ZA.

(2) The development of the interlanguage discourse of Chinese EFL learners undergoes the process of discourse transfer.

\section{Method}

\subsection{Participants}

The subjects of this study are 90 Chinese students of English in China. Group 1 are 30 high school first-year students(15-17 years old), while Group 2 are 30 first-year university English major students(18-21 years old) and Group 3 are 30 first-year postgraduate students of English major(23-26 years old) at the same university of Group 2. Since there are three or four years of difference in formal learning between each of the groups, it is assumed that they represent three proficiency levels of beginning, intermediate and advanced. Of course the dividing line is by no means absolute.

\subsection{Instrument and Procedure}

The task was designed to compare the English of Chinese university students with the English passages from textbooks, with the passages being translated into Chinese as the source text for the task given to the students. The task was a translation of 2 pieces of Chinese discourse into English, each of which consisted of two paragraphs that are characterized by typical Chinese TP features, namely, topic chains and zero anaphora. These 2 pieces of Chinese discourse were translated from 2 pieces of English discourse which were excerpted from primary school textbooks Go for It (Book 3) (By People's Education Press, 2002) and Essential English for Foreign Students (Book 1) (By C. E. Eckersley, Longmans., 1955). This task was designed to elicit the learners' production of anaphora. There were 6 topic chains in which 26 anaphors including zero, pronominal and nominal anaphors were identified in the two pieces of Chinese discourse. We can refer to Example (1) in 2.2 which is the second piece of Chinese discourse for more information. That piece of discourse is made up of two topic chains. In the first topic chain which contains six zero anaphors the overt identical NP "na liang che (that car)" is the topic.

The difficult English words were provided to the participants in order to ensure that these words would not prevent them from completing the task successfully. After reading the instructions and making sure they understood them, the participants proceeded with the task. A maximum of 20 minutes was allowed for this task. Maybe some students had used the books as course texts but they would not have remembered all the details or that even if they did remember some, the results suggest that less proficient students were much more influenced by zero anaphora than the more proficient ones were. Data for this investigation were collected in the participants' regular classes. All the participants were asked to perform the task independently.

\subsection{Data Analysis}

Raw data in the task were classified, calculated and tabulated into various tables for data analysis. The frequencies of various types of anaphora employed in the task by Chinese EFL learners were counted. The following furnishes an example of the data analysis for the second piece of Chinese discourse of the task:

(1) Beginning Proficiency Group: That car is too expensive, the color is not good. I don't like $\boldsymbol{\varnothing}$ and don't want to buy $\boldsymbol{\emptyset}$. I went to see $\boldsymbol{\varnothing}$ yesterday and I drove $\boldsymbol{\varnothing}$ a little time, but still dislike $\boldsymbol{\varnothing}$.(Number of ZA: 5; other: 0)

(2) Intermediate Proficiency Group: That car is too expensive, the color is not good. I don't like $\boldsymbol{\varnothing}$ and don't want to buy $\varnothing$. I went to see it yesterday and I drove it a little time, but I still dislike it.(Number of ZA: 2; other: 3)

(3) Advanced Proficiency Group: That car is too expensive, the color is not good. I don't like it and don't want to buy it. I went to see it yesterday and I drove it a little time, but I still dislike it.(Number of ZA: 0; other: 5)

The data analysis was conducted to examine the number and proportion of ZA used by the three participant groups when performing the translation task. It was focused on the inappropriate use of ZA in discourse. For the translation production, every piece of discourse produced by the participants was compared with its original version on the textbook to identify the zero anaphors produced by the participants and the total number of wrong ZA was computed. For example, in the sample above a participant of the beginning level employed 5 zero anaphors in the translation of the second piece of Chinese discourse where pronominal anaphors were necessary. Whereas, a participant of the 
intermediate level employed 2 zero anaphors wrongly and 3 pronominal anaphors properly and the participant of the advanced level made no mistake in employing anaphora. In the analysis the results of the three groups were compared in order to reveal whether there was a similarly strong tendency among beginning, intermediate and advanced learners in the production of topic-prominent constructions. With respect to data analysis, descriptive statistics such as percentages are employed to describe relative proportions and tendencies, and at times the data is assessed by the help of the software packages SPSS. A one way ANOVA was undertaken to measure significant differences between each level.

\section{Results}

\subsection{Distributions of Different Types of Anaphora in the Test among the Three Groups}

The distribution of types of anaphora used by the three participant groups is graphically represented in Figure 1. The figure shows that the Beginning and Intermediate groups used the ZA more extensively than the Advanced group, who in turn used the Pronominal and Nominal Anaphora more frequently.

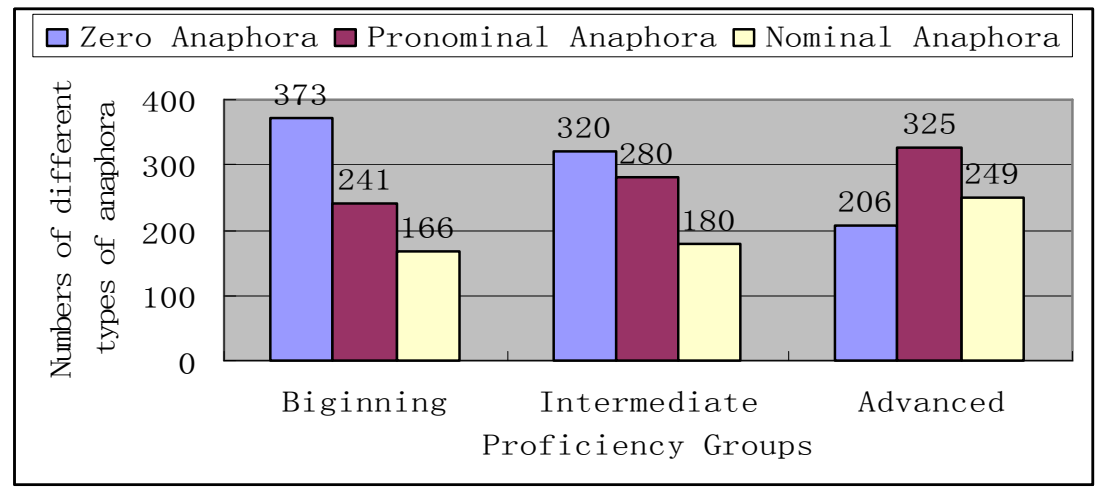

Figure 1. Numbers of Different Types of Anaphora in the Test

\subsection{Specific Distributions of ZA in the Test among the Three Groups}

Table 1 displays the proportion of the number and percentage of ZA in all the test items.

Table 1. The Number and Percentage of ZA in the Test

\begin{tabular}{lcc}
\hline Proficiency Groups & Number of ZA & Percentage of ZA \\
\hline Beginning $(\mathrm{n}=30)$ & 373 & $47.82 \%$ \\
Intermediate $(\mathrm{n}=30)$ & 320 & $41.03 \%$ \\
Advanced $(\mathrm{n}=30)$ & 206 & $26.15 \%$ \\
\hline
\end{tabular}

Table 1 shows the number and percentage of ZA in the test. For example, 373 zero anaphors altogether were identified in the interlanguage of the 30 Beginning learners and the percentage of ZA is $373 / 30 * 26$ (number of all types of anaphora in the test $)=47.8 \%$. From the table we learn that the subjects of lower levels demonstrated the tendency of producing more zero anaphora in the test. As the learners' L2 proficiency increased, such a tendency gradually becomes weaker though each of the items makes up a different proportion in terms of the production of topic prominence. Although all the subjects had learned English for 3 up to 10 years, they still displayed a tendency to rely on Chinese topic-prominent structures.

\subsection{Multiple Comparisons between_Proficiency Levels}

The one way ANOVA was conducted to measure the significant difference among levels. The results (see table 2) demonstrate significant difference occurs in employing ZA across the three proficiency groups $(\mathrm{F}=57.466, \mathrm{P}=0.000)$.

Table 2. Result of One Way ANOVA

\begin{tabular}{lccccc}
\hline & Sum of Squares & df & Mean Square & F & Sig. \\
\hline Between Groups & 485.489 & 2 & 242,744 & 57.466 & .000 \\
Within Groups & 367.500 & 87 & 4.224 & & \\
Total & 852.989 & 89 & & & \\
\hline
\end{tabular}

To be specific, the further LSD post hoc analysis was undertaken and the result of multiple comparisons between proficiency levels is shown in Table 3: 
Table 3. Result of Multiple Comparisons between_Proficiency Levels

\begin{tabular}{llcl}
\hline lever (I) & level $(\mathrm{J})$ & Mean Difference $(\mathrm{I}-\mathrm{J})$ & sig \\
\hline Beginning & Intermediate & $1.767^{\mathrm{a}}$ & .001 \\
& Advanced & $5.567^{\mathrm{a}}$ & .000 \\
Intermediate & Beginning & $-1.767^{\mathrm{a}}$ & .001 \\
& Advanced & $3.800^{\mathrm{a}}$ & .000 \\
Advanced & Beginning & $-5.567^{\mathrm{a}}$ & .000 \\
& Intermediate & $3.800^{\mathrm{a}}$ & .000 \\
\hline
\end{tabular}

a: The mean difference is significant at the 0.05 level

Table 3 displays that the difference between Beginning Level and Advanced Level and that between Intermediate Level and Advanced Level, in terms of ZA are the most significant with their value $p=0.000$, while the difference between Beginning Level and Intermediate Level is also statistically significant $(\mathrm{p}=0.001)$. So the comparisons show that the difference between every two proficiency levels is significant, especially between Beginning level and Advanced Level.

At the beginning level, many zero anaphors were employed in the interlanguage of all the subjects. At the intermediate level, relatively fewer zero anaphors were produced by the subjects than at the beginning level, but the percentage is also very high - up to about $50 \%$. Generally speaking, the zero anaphors produced by advanced subjects are obviously fewer than those of the other two groups. The proportion of such structures has decreased by almost one-third of that of intermediate level, demonstrating that they were less influenced by their NL when using the L2. They were more likely to employ their monitoring systems and a variety of learning strategies during the production of discourse.

The data from the three proficiency levels has shown that all the subjects at each proficiency level were influenced by the topic-prominent features from their NL, indicating that topic-prominent constructions in Chinese are transferable. When they were required to produce English discourse, all the subjects produced, more or less, some topic-prominent constructions due to the influence of their native language. There is a general tendency from topic prominence to subject prominence with the increase of the learners' English proficiency level and it is evident that their interlanguage will become more like the target language.

\section{Discussion}

This study seeks to answer the two research questions: Do learners decrease the choice of TP structures with the increase of use of SP structures along with their proficiency levels? Will the ZA be transferred to the interlanguage, and result in overgeneralization of ZA and discourse transfer?

\subsection{Findings about Research Question 1}

According to the results of the present study, the beginning learners showed predominant use of TP features, and the use of such features gradually decreased, in accordance with their L2 proficiency. The results of the test have demonstrated a general shift from the use of zero to Pronominal to Nominal anaphors in the interlanguage of Chinese learners on the discourse level as their proficiency level increased. The results show that the interlanguage discourse of the Chinese students of the three proficiency levels is characterized by topic-prominent constructions. Even the advanced learners are still subject to the influence of the topic prominence feature from Chinese. It clearly indicates L1 transfer effect as the topic-prominent feature of interlanguage production prevails over a relatively long period of time for learners with a topic-prominent L1 background like the Chinese students in this study, suggesting possible fossilization (Selinker, 1972).

The present findings do not support Fuller \& Gundel's (1987) study regarding an early universal stage of topic prominence in SLA, but rather support the view that L1 features are transferable in SLA and that with growing L2 proficiency, learners gradually approximate target language norms (Cai, 1998a\&b; Givón, 1983; Jin, 1994; Sasaki, 1990; Shi, 1989; Yang, 2008; Yip, 1995).

Schachter (1983) argues that "it is not likely to be the case that the process of second language acquisition will prove to be the same process as in the first language acquisition case" (P.256). She points out that one obvious source is the learner's first language and the facilitating and interfering effects it produces. It is clear to anyone who takes the trouble to look at the production of a non-native speaker of a language that there is a first language, or transfer effect (Schachter, 1983). Actually the reliance on the knowledge of the native language, especially the NL-related typological differences, is a universal learning strategy, which is obvious in the process of second language acquisition.

\subsection{Findings for Research Question 2}

In discussing discourse transfer, Odlin(1989) dealt with it from structural factors and nonstructural factors. This is because discourse involves a wide array of nonstructural as well as structural characteristics. Chinese discourse frames seem to be intruding into English discourse and result in discourse transfer. If many TP structures are present in the text, the impression conveyed to the native-speaker reader of English will be of disjointed and fragmented development of the messages embodied in the discourse. 
The none-native-like English discourse produced by Chinese learners could be related to absence of adequate cohesive ties. This is not surprising if, in the deep structure, the learner conceives his TL (English) surface coding in a topicprominent manner. In a topic-prominent NL, a topic stands at the head of the discourse and the ensuing discourse is taken by the producer and the receiver to be related to it until a new topical referent is introduced. Subject-prominent languages like English, however, undergo a complicated process of textualization to achieve a tightly-spun, surface structure.

As discussed earlier, discourse transfer is the use of some of the discourse patterns in the learner's L2 in the same way in which they are employed in the learner's L1. It then follows that the learners are likely to negatively transfer the norms from their L1 to their L2 production largely due to their knowledge gaps about the L2 discourse norms. First, if learners are unaware of the L2 norms in particular contexts, they will be unable to produce the equivalent grammatical forms; in other words, a mismatch arises between their grammatical knowledge and the demands of particular discourse contexts. Therefore, they may resort to the simpler grammatical forms they are more confident about but they may not be grammatically appropriate. Second, learners may have acquired the grammatical structures of certain utterances in the discourse. However, they may not understand or become aware of their discursive meanings in different contexts. Even in the data of advanced learners, discourse transfer still occurs, as they have not yet acquired the equivalent L2 forms of discourse in some contexts. In order to play it safe, they tend to fall back on L1 literal translation when their "linguistic resilience" falls short. Transferring their L1 discourse norms in the form of literal translation and direct formmeaning mapping appears to be a safe strategy to help them finish the task.

\section{Conclusion}

The present study has provided some preliminary evidence that the process of acquiring English by Chinese learners may be influenced by L1-L2 typological differences. Some conclusions can be drawn from this study. First of all, TP properties in the interlanguage of Chinese students are evident. Second, ZA exists pervasively in the interlanguage of Chinese students of English at different proficiency levels. The ZAs in the interlanguage of Chinese students of English are mostly motivated by NL-related typological transfer and discourse transfer. Third, interlanguage discourse of Chinese EFL learners also reflects the characteristics of second language acquisition process from topic-prominence to subject-prominence. Han (2010) has made longitudinal studies of fossilization, so similarly for future research, a longitudinal study is needed to examine the developmental sequences of typological features in SLA.

\section{Acknowledgments}

Special thanks are due to Dr Henriëtte Hendriks at University of Cambridge and Liming Yu at Shanghai Jiaotong University who helped to revise the manuscript. We are also grateful to Zhe Sun for her help during data collection.

\section{References}

Bartelt, H. G. (1992) Transfer and variability of rhetorical redundancy in apachean English interlanguage. In S. M. Gass \& L. Selinker (Eds) Language transfer in language learning (pp. 101-118). Amsterdam: J. Benjamins Publication Co.

Cai, J. T. (1998a) The influence of Chinese topic-prominent features on Chinese EFL learners' compositions. Foreign Language Teaching and Research, 4(3), 17-21.

Cai, J. T. (1998b) L1 Transfer and Topic-prominence Structure. Journal of Jiefangjun University of Foreign Languages, 6(3), 15-19.

Chen, P. (1987) Discourse analysis of Chinese zero anaphora. Chinese, 5(3), 16-19.

Chu, C. C. (1998) A Discourse Grammar of Mandarin Chinese. New York: Peter Lang Publishing, Inc.

Eckersley, C. E. (1955) Essential English for Foreign Students. London: Longmans.

Fuller, J. W. \& Gundel, J. K. (1987) Topic-prominence in interlanguage. Language Learning, 37(2), 1-18.

Givón, T. (1983) Topic continuity in discourse: an Introduction. In Givón, T. (Ed) Topic Continuity in Discourse: A Quantitative Cross-language Study (pp. 1-41). Amsterdam: J. Benjamins.

Han, Z. (2010). Grammatical inadequacy as a function of linguistic relativity: A longitudinal case study. In Z. Han \& T. Cadierno (Eds), Linguistic relativity in second language acquisition: Evidence of first language thinking for speaking (pp. 154-182). Clevedon, U.K.: Multilingual Matters.

Huang, J. (1984) On the typology of zero anaphora. Language Research, 20(3), 85-105.

Huang, J. (1989) Pro-drop in Chinese: A generalized control theory. In Jaeggli, O. \& K, Safir. (Eds) The Null Subject Parameter (pp. 185-214). Dordrecht: Kluwer Academic Publishers.

Institute of Curriculum Research. (2002) Go for It (Book 3). Beijing: People's Education Press.

Jin, H. G. (1994) Topic-prominence and subject-prominence in L2 acquisition: Evidence of English to Chinese typological transfer. Language Learning, 44(4), 101-122.

Jung, E. H. (2004) Topic and subject prominence in interlanguage development. Language Learning, 54(4), 713-738.

Kasper, G. (1992). Pragmatic transfer. Second Language Research, 8(3), 203-231. 
Kasper, G. \& Schmidt, R. (1996) Developmental issues in interlanguage pragmatics. Studies in Second Language Acquisition, 18(2), 149-169.

Kellerman, E. (1983). Now you see it, now you don't. In S. M. Gass, \& L. Selinker (Eds), Language transfer in language learning (pp. 112-134). Rowley, Mass.: Newbury House.

Kellerman, E. (1995) Crosslinguistic influence: Transfer to nowhere? Annual Review of Applied Linguistics, 15, 125150 .

Li, C. \& Thompson, S. A. (1976) Subject and topic: A new typology. In Li, C. (Ed) Subject and Topic (pp. 457-489). New York: Academic Press.

Li, C. \& Thompson, S. A. (1981) Mandarin Chinese: A Functional Reference Grammar. Los Angeles: University of California Press.

Li, W. D. (2005) Topic Chains in Chinese: A Discourse Analysis and Applications in Language Teaching. Muenchen, Germany: Lincom Europa.

Odlin, T. (1989) Language Transfer: Cross-linguistic Influence in Language Learning. Cambridge: Cambridge University Press.

Rutherford, W. (1983) Language typology and language transfer. In S. M. Gass \& L. Selinker (Eds) Language Transfer in Language Learning (pp. 358-470). Rowley, MA: Newbury House.

Sasaki, M. (1990) Topic prominence in Japanese EFL students' existential constructions. Language Learning, 40(4), 337-368.

Schachter, J. (1983) A new account of language transfer. In S. Gass \& L. Selinker (Eds) Language Transfer in Language Learning (pp. 98-111). Rowley, MA: Newbury House.

Schachter, J. \& W. Rutherford. (1979) Discourse function and language transfer. Working Papers in Bilingualism, 19, $1-12$.

Selinker, L. (1972). Interlanguage. International Review of Applied Linguistics, 10, 209-231.

Shi, D. X. (1989) Topic chain as a syntactic category in Chinese. Journal of Chinese Linguistics, 17, 223-261.

Tsao, F. (1977) Subject and topic in Chinese. In Robert Cheng, Li Ying-che \& Tang Ting-chi (Eds) Proceedings of Symposium on Chinese Linguists (pp. 167-195). Linguistic Institute of the Linguistic Society of America. Taipei: Student Book Company.

Tsao, F. (1979) A Functional Study of Topics in Chinese: The First Step towards Discourse Analysis. PhD thesis, Ithaca, New York: Cornell University.

Tsao, F. (1990) Sentence and Clause Structure in Chinese: A Functional Perspective. Taipei, Taiwan: Student Book

Wang, J. (2002) Researches on text syntax in Mandarin Chinese. PhD thesis, Peking University.

Wang, J. (2004) Syntactic principle of topic-chain in Mandarin Chinese. Language Teaching and Linguistic Studies, $3(2), 30-39$.

Wang, Y. K, Chen, Y. S. \& Hsu, W. L. (1998) Empirical study of Mandarin Chinese discourse analysis: an event-based approach, to appear in 10th IEEE International Conference on Tools with Artificial. Intelligence (ICTAI'98).

Wu, S. H. (2001) Discourse transfer phenomena as manifested in interlangauge performance of four Chinese ESL university-level students: An analytic/interpretive investigation of what Chinese learners bring to NS-NNS interaction. Retrieved, $15^{\text {th }}$ March, 2008, from: http://pqdd.sinica.edu.tw/cwdaoeng/servlet/advanced?query=9999461

Yang, L. R. (2008) Topic Prominence in Typological Interlanguage Development of Chinese Students' English. PhD thesis, Shanghai Foreign Studies University.

Yeh, C. L. \& Chen, Y. C. (2003) Zero anaphora resolution in Chinese with partial parsing based on centering theory. In Proceedings of IEEE NLP-KE03, Beijing, China.

Yip, V. (1995) Interlanguage and typology: The case of topic-prominence. In L. Eubank., L. Selinker \& M. S. Smith (Eds) The Current State of Interlanguage (pp.17-30). Amsterdam: J. Benjamins. 